\title{
Rapid efficacy of mirtazapine in the treatment of hyperemesis gravidarum with esophagus perforation and ketonuria in a normoglycemic patient: a case report
}

\author{
Aysegul Tasdelen Kul ${ }^{1}$, Ibrahim Gundogmus ${ }^{1}$, Mikail Burak Aydin ${ }^{1}$ \\ ${ }^{1}$ Health Science University, Gulhane Training and Research Hospital, Department of Psychiatry, Ankara - Turkey
}

\begin{abstract}
Hyperemesis gravidarum is a medical condition that may cause serious consequences for fetus and mother. The treatment regimen in patients with severe and treatment-resistant conditions is unclear. While antiemetics are known to be used for hyperemesis gravidarum in the literature, mirtazapine has been used effectively in some treatment-resistant cases. On the other hand, to the best of our knowledge, no reports on the efficacy of mirtazapine in cases of severe and treatment-resistant hyperemesis gravidarum have been published in the literature. The aim of our report was to present a successful treatment with mirtazapine for a 28-year-old pregnant patient who developed esophageal perforation and ketonuria while being normoglycemic due to severe and treatment-resistant hyperemesis gravidarum. This case revealed that mirtazapine may be effective even in severe cases of hyperemesis gravidarum. In addition, the effectiveness of mirtazapine in the treatment of hyperemesis gravidarum has been confirmed. However, the appropriateness of using mirtazapine in the treatment of pregnant patients needs to be discussed.
\end{abstract}

Keywords: Esophagus perforation, hyperemesis gravidarum, ketonuria, mirtazapine, normoglycemic, severe nausea

\section{INTRODUCTION}

Mirtazapine is an orally administered tetracycline antidepressant increasing both noradrenergic and serotonergic activity $(1,2)$. It is frequently used in clinical practice especially for the treatment of depression and anxiety disorder as it is effective, potent, and well tolerated (3). In addition, successful use in the treatment of sleeping disorders, weight loss, and anorexia nervosa has been reported $(1,4)$. Recent publications have indicated that mirtazapine can also achieve effective results in the treatment of nausea/ vomiting $(5,6)$.

Hyperemesis gravidarum, a medical condition characterized by severe nausea and vomiting, can cause serious consequences for the fetus and the mother $(7,8)$. An estimated $78-89 \%$ of pregnant women experience hyperemesis gravidarum $(8,9)$. As a result, various medical conditions that may require hospitalization, such as dehydration, starvation, hypoglycemia,

How to cite this article: Tasdelen Kul A, Gundogmus I, Aydin MB. Rapid efficacy of mirtazapine in the treatment of hyperemesis gravidarum with esophagus perforation and ketonuria in a normoglycemic patient: a case report. Dusunen Adam The Journal of Psychiatry and Neurological Sciences 2020;33:206-209.

Correspondence: Ibrahim Gundogmus, Gulhane Training and Research Hospital, Department of Psychiatry, Emrah Mahallesi, Gen. Dr. Tevfik Saglam Cd. No:11, 06010 Kecioren, Ankara - Turkey

E-mail: dribrahim06@gmail.com

Received: May 06, 2019; Revised: January 10, 2020; Accepted: March 07, 2020 
hypopotassemia and even esophagus perforation or medical abortion have been observed $(7,8)$. Nausea and vomiting during pregnancy are mostly believed to be related either to hormonal changes or to psychological stress. Other organic causes of vomiting need to be excluded before diagnosis (8). Since the pathophysiology of nausea and vomiting in pregnancy is not clear, there is no scientific treatment for its causes; treatments are usually intended to relieve the symptoms while they occur. Application of antiemetics with liquid/electrolyte and vitamin supplements is the first option in order to avoid negative consequences (10). Other treatment options include a wide range of interventions from antiemetic drugs to psychotherapies (11). In addition, the number of publications reporting mirtazapine having been used effectively in the treatment of hyperemesis gravidarum is not insignificant $(2,12,13)$. However, to the best of our knowledge, there is no report revealing the efficacy of mirtazapine in cases of hyperemesis gravidarum with esophagus perforation.

Here, we present the case of a 28 -year-old woman who experienced esophageal perforation due to treatment-resistant hyperemesis gravidarum and was successfully treated with mirtazapine.

\section{CASE}

A 28 -year old patient was gravida 4 with parity 3 . She was a high school graduate housewife. The patient was admitted to our hospital's obstetric clinic with complaints of severe nausea and vomiting. She had frequent abdominal cramps and could not endure them anymore. After examination, a diagnosis of esophageal perforation was made and treatment was initiated accordingly. The patient had symptoms of minor depression and anxiety before the pregnancy. Complaints of nausea and vomiting started in the $2^{\text {nd }}$ week of pregnancy, and the patient was diagnosed with hyperemesis gravidarum in the $6^{\text {th }}$ week. Prokinetics including $8 \mathrm{mg} / \mathrm{d}$ ondansetron, $8 \mathrm{mg} / \mathrm{d}$ prednisolone, and $10 \mathrm{mg} / \mathrm{d}$ metoclopramide were administered for over 1 month. However, there was no relief of nausea and vomiting. By the $8^{\text {th }}$ week, the patient had lost 8.5 $\mathrm{kg}$ compared to her pre-pregnancy weight. The normoglycemic patient's urine was positive for ketones. During pregnancy, the patient was exposed to social and familial stressors and complaints of hyperemesis gravidarum increased. Medical abortion was planned because the patient's state and the vital signs of the fetus deteriorated. The patient was finally referred to a psychiatry clinic. After detailed history and psychological examination, the patient was not diagnosed with any psychopathology according to the DSM-5 diagnostic criteria. However, she was recommended to use mirtazapine. The patient was able to tolerate food and beverages for the first time within two hours after receiving the first $15 \mathrm{mg}$ of mirtazapine. One week later, complaints of nausea and vomiting decreased significantly. Oral mirtazapine treatment was continued for 60 days. After termination of the mirtazapine treatment, the nausea level was tolerable for the patient. The fetus was within the normal limits at monthly ultrasonographic control examinations during the use of mirtazapine and after discontinuation. The mother's weight gain was normal. She gave birth by vaginal delivery at 38 weeks of gestation. The baby's weight, height, and head circumference at birth were within normal percentiles. No pathologies were diagnosed. The baby was feeding sufficiently. There were no birth complications for the mother. She had no complaints at follow-up after delivery.

\section{DISCUSSION}

Hyperemesis gravidarum is a condition characterized by severe nausea and vomiting in pregnant women and the treatment protocol is still not clear. We have presented the successful treatment with mirtazapine of a patient suffering severe hyperemesis gravidarum with ketonuria while being normoglycemic and esophageal perforation. We believe our case to be significant because ketonuria and esophageal perforation even suggested medical abortion; a very severe case of hyperemesis gravidarum showed a very fast response.

Although nausea and vomiting during pregnancy are considered to be normal, symptoms may range from women's discomfort to medical abortion (9). Consequently, dehydration, starvation, hospitalization, hypoglycemia, hypopotassemia, or even esophagus perforation or medical abortion may occur. However, these symptoms are known to vary individually (7). In our case, while there are many different therapies described in the literature, we used a treatment with mirtazapine, an antidepressant, for a very severe case of hyperemesis gravidarum. The reason for choosing mirtazapine for our patient was that it was shown in the relevant literature to be effective against hyperemesis gravidarum (2,13-15), and our patient benefited from the mirtazapine treatment as had been expected in the light of the literature. What distinguished our case from previous reports was the presence of relatively severe case indicators such as the development of esophageal 
perforation and ketonuria in a normoglycemic patient, and the suggestion of medical abortion. However, we think that with mirtazapine treatment, the patient's symptoms receded faster than expected. The most likely mechanism of action for a successful treatment of hyperemesis gravidarum with mirtazapine may be blocking the 5HT3 receptor, similar to the antiemetic ondansetron $(16,17)$.

Another reason for choosing mirtazapine in our case was that this substance does not cause intrauterine fetal loss after the first trimester. There was no risk of teratogenicity and there were no developmental differences compared to controls (12). In addition, mirtazapine may be therapeutic for the psychological effects of pregnancy and hyperemesis gravidarum (14). Ondansetron tried in our patient to achieve 5HT3 receptor blockade was ineffective for hyperemesis gravidarum, whereas mirtazapine was found to be effective. Psychological factors such as anxiety and depression may play a role in the pathogenesis and prevention of hyperemesis. Therefore, considering the effect of psychological factors in the treatment of hyperemesis, mirtazapine with additional 5-HT1astimulation may be selected to outperform selective 5HT3-receptors (18).

In conclusion, our study showed that mirtazapine may be effective even in cases of severe hyperemesis gravidarum. Thus, the effectiveness of mirtazapine in the treatment of hyperemesis gravidarum has been confirmed. However, the use of mirtazapine in the treatment of pregnant patients needs to be discussed. Clinicians should be aware that mirtazapine is an important alternative in the treatment of disorders such as hyperemesis gravidarum during pregnancy and anxiety and depressive disorder in daily practice. A prospective design, larger sample and longitudinal studies will be beneficial to confirm the safety of mirtazapine.

\begin{tabular}{|c|c|c|}
\hline \multicolumn{2}{|c|}{ Contribution Categories } & Author Initials \\
\hline \multirow{4}{*}{ Category 1} & Concept/Design & M.B.A., I.G. \\
\hline & Literature review & I.G., M.B.A. \\
\hline & Data analysis/Interpretation & M.B.A., I.G., A.T.K. \\
\hline & Case follow-up (if applicable) & A.T.K., I.G. \\
\hline \multirow{2}{*}{ Category 2} & Drafting manuscript & M.B.A., I.G. \\
\hline & Critical revision of manuscript & A.T.K., I.G. \\
\hline Category 3 & Final approval and accountability & M.B.A., I.G., A.T.K. \\
\hline \multirow{2}{*}{ Other } & Technical or material support & I.G., M.B.A. \\
\hline & Supervision & A.T.K., M.B.A., I.G. \\
\hline
\end{tabular}

Informed Consent: Written informed consent was obtained from the patient.
Peer-review: Externally peer-reviewed.

Conflict of Interest: The authors declared no conflict of interest.

Financial Disclosure: There has been no external funding.

\section{REFERENCES}

1. de Boer TH, Nefkens F, van Helvoirt A, van Delft AM. Differences in modulation of noradrenergic and serotonergic transmission by the alpha-2 adrenoceptor antagonists, mirtazapine, mianserin and idazoxan. J Pharmacol Exp Ther $1996 ; 277: 852-860$

2. Guclu S, Gol M, Dogan E, Saygili U. Mirtazapine use in resistant hyperemesis gravidarum: report of three cases and review of the literature. Arch Gynecol Obstet 2005; 272:298-300.

3. Ozcankaya R, Acar A. A comparison of amitriptyline and mirtazapine side effects in depression treatment. Bull Clin Psychopharmacol 2001; 11:17-27.

4. Hrdlicka M, Beranova I, Zamecnikova R, Urbanek T. Mirtazapine in the treatment of adolescent anorexia nervosa. Case-control study. Eur Child Adolesc Psychiatry 2008; 17:187189.

5. PaeCU. Low-dose mirtazapine may be successful treatment option for severe nausea and vomiting. Prog Neuropsychopharmacol Biol Psychiatry 2006; 30:1143-1145.

6. Kim SW, Shin IS, Kim JM, Kang HC, Mun JU, Yang SJ, et al. Mirtazapine for severe gastroparesis unresponsive to conventional prokinetic treatment. Psychosomatics 2006; 47:440442 .

7. Simsek Y, Celik O, Yilmaz E, Karaer A, Yildirim E, Yologlu S. Assessment of anxiety and depression levels of pregnant women with hyperemesis gravidarum in a case-control study. J Turk Ger Gynecol Assoc 2012; 13:32-36.

8. Kender EE, Yuksel G, Ger C, Ozer U. Eating attitudes, depression and anxiety levels of patients with hyperemesis gravidarum hospitalized in an obstetrics and gynecology clinic. Dusunen Adam The Journal of Psychiatry and Neurological Sciences 2015; 28:119-126

9. Chan RL, Olshan AF, Savitz DA, Herring AH, Daniels JL, Peterson HB, et al. Maternal influences on nausea and vomiting in early pregnancy. Matern Child Health J 2011; 15:122-127.

10. Buyukkurt S, Demir SC, Ozgunen FT, Evruke IC, Kadayifci O, Guzel AB. Evaluation and Treatment of the Patients with Nausea and Vomiting in Pregnancy: Review. Turkiye Klinikleri J Gynecol Obst 2008; 18:106-116.

11. Kavakci O, Yenicesu GI. Eye movement desensitization and reprocessing [EMDR] for hyperemesis gravidarum: a case series. Dusunen Adam The Journal of Psychiatry and Neurological Sciences 2014; 27:335-341.

12. Saks B. Mirtazapine: treatment of depression, anxiety, and hyperemesis gravidarum in the pregnant patient. A report of 7 cases. Arch Womens Ment Health 2001; 3:165-170.

13. Naguy A. Mirtazapine for major depression developed after hyperemesis gravidarum. Am J Ther 2019; 26:e661-e662. 
14. Rohde A, Dembinski J, Dorn C. Mirtazapine (Remergil) for treatment resistant hyperemesis gravidarum: rescue of a twin pregnancy. Arch Gynecol Obstet 2003; 268:219-221.

15. Uguz F. Low-dose mirtazapine in treatment of major depression developed following severe nausea and vomiting during pregnancy: two cases. Gen Hosp Psychiatry 2014; 36:125.e5-6.

16. Montgomery SA. Safety of mirtazapine: a review. Int Clin Psychopharmacol 1995; 10:37-45.
17. Theobald DE, Kirsh KL, Holtsclaw E, Donaghy K, Passik SD. An open-label, crossover trial of mirtazapine (15 and $30 \mathrm{mg}$ ) in cancer patients with pain and other distressing symptoms. J Pain Symptom Manage 2002; 23:442-447.

18. Schwarzer V, Heep A, Gembruch U, Rohde A. Treatment resistant hyperemesis gravidarum in a patient with type 1 diabetes mellitus: neonatal withdrawal symptoms after successful antiemetic therapy with mirtazapine. Arch Gynecol Obstet 2008; 277:67-69. 